\title{
Ultra-sonografia para predição da composição da carcaça de bovinos jovens
}

\author{
Liliane Suguisawa1, Wilson Roberto Soares Mattos ${ }^{2}$, André Alves de Souza1, Antônio Carlos \\ Silveira $^{3}$, Henrique Nunes de Oliveira $^{3}$, Mário de Beni Arrigoni ${ }^{3}$, Daniela Cristina Morales Burini ${ }^{1}$ \\ 1 Pós-graduandos em Nutrição e Produção Animal - FMVZ/UNESP/Botucatu-SP \\ 2 Depto. Produção Animal - USP/ESALQ, C.P. 09, CEP: 13418-220 - Piracicaba/SP \\ ${ }^{3}$ Depto. Melhoramento Genético e Nutrição Animal - FMVZ/UNESP, C.P. 560, CEP: 18618-000 - Botucatu/SP.
}

RESUMO - Neste estudo, avaliou-se a utilização da ultra-sonografia como técnica para predição da composição da carcaça de 115 bovinos jovens (Nelore, 1/2 Angus Nelore, 1/2 Simental Nelore e Canchim), com peso inicial médio de $329 \mathrm{~kg}$, de dois tamanhos à maturidade (pequeno e grande), criados no sistema de produção do novilho superprecoce. Após 120 dias de confinamento, foram realizadas a pesagem e a medida da área de olho-de-lombo (AOL) e da gordura subcutânea (ECG), via ultra-sonografia. Após o abate, foram registradas as medidas de AOL e ECG na carcaça, os pesos de traseiro, dianteiro, cortes cárneos comerciais e a composição corporal dos animais. Foram calculados os rendimentos de carcaça, de cortes cárneos e de traseiro, não se observando diferença na composição entre os dois grupos de tamanho à maturidade, provavelmente em razão da pequena variação entre eles. Embora a ultra-sonografia não tenha apresentado alta precisão na predição da musculosidade da carcaça e do rendimento de cortes cárneos, os coeficientes de determinação das equações de predição da composição da carcaça foram semelhantes, e algumas vezes superiores (quantidade de ossos), aos obtidos nas equações em que se utilizaram as medidas na carcaça após o abate, demonstrando que a ultra-sonografia pode ser utilizada para predição da composição da carcaça de bovinos de corte em determinadas situações.

Palavras-chave: cortes cárneos, gordura, musculosidade, ossos, rendimento

\section{Prediction of carcass composition of steers using ultrasound measurements}

\begin{abstract}
This study was conducted to evaluate the use of ultrasound measurements to predict carcass composition of 115 steers (Nellore, $1 / 2$ Angus x Nellore, 1/2 Simental x Nellore, and Canchim) with different frame sizes (small and large) and average initial body weight of $329 \mathrm{~kg}$. After 120 days in a feedlot, animals were weighed followed by ultrasound measurements of rib eye area (RA) and fat thickness (FT). Animals were slaughtered and measurements of carcass RA and FT, weights of hindquarter, forequarter, and commercial cuts, and determination of body composition were done. In addition, yields of carcass, commercial cuts, and hindquarter were calculated and no significant differences between frame sizes were found for these variables. Ultrasound measurements were not precise predicting carcass muscle content and yields of commercial cuts in this trial. However, determination coefficients from regression equations of carcass composition using ultrasound were similar and sometimes higher (e.g. bone content) than those from regression equations of carcass composition, in which measurements were taken after slaughter. Therefore, ultrasound measurements can be used to predict carcass composition of beef cattle for some variables.
\end{abstract}

Key Words: bone, fat, muscle, retail yield, yield grade

\section{Introdução}

A determinação da composição corporal é de grande importância para avaliação de grupos genéticos e de tratamentos nutricionais visando ao crescimento animal e à determinação de exigências nutricionais. Entretanto, é bastante trabalhosa e de custo elevado, tornando sua execução por métodos diretos inviável, mesmo em rotinas experimentais (Lanna, 1988). Diversas metodologias foram desenvolvidas para possibilitar a identificação de alterações na composição corporal decorrentes da raça, do sexo e do manejo nutricional, entre outros. Lush (1926) foi o primeiro pesquisador a concluir que a estimativa da composição da carcaça a partir do corte de todas as costelas era bastante acurada. Após sua pesquisa, outros técnicos propuseram a utilização do corte da secção da 9aa $11^{\underline{a}}$ costelas, e não de todo o corte, contribuindo para maior precisão nas estimativas e menor depreciação da carcaça (Hopper, 1944). Posteriormente, foi definida a metodologia de Hankins \& Howe (1946) para determinação da composição física do corte da $9^{\mathrm{a}}$ à $11^{\mathrm{a}}$ costelas. Esta técnica estima com precisão a composição de carcaça de bovinos e seus resultados têm sido validados em inúmeros trabalhos (Fontes; 1995; Lanna et al., 1995; Alleoni et al., 1997; Jorge et al., 1997; Jorge \& Fontes, 2001). 
Entretanto, a utilização de quaisquer metodologias que não impliquem necessariamente no abate do animal apresenta inúmeras vantagens, destacando-se a possibilidade de repetição no mesmo animal em caso de dúvida e a redução dos custos com mão-de-obra e dos prejuízos ocasionados pela depreciação da carcaça. Segundo Fisher (1997), a ultra-sonografia começou a ser avaliada como técnica para a predição da composição de carcaça de bovinos de corte em 1950, sendo considerada uma das mais baratas e de mais fácil aplicação. Apesar de existirem resultados razoavelmente acurados na utilização da técnica de ultrasonografia para a predição da composição de carcaça em bovinos, permanece ainda obscura a definição das variáveis que devem ser adotadas nas equações de predição, pois muitas vezes são preconizadas características muito distintas (peso vivo, idade, raça, altura da garupa, medidas de espessura da camada de gordura subcutânea [ECG] e área de olho-de-lombo [AOL] por ultra-sonografia e na carcaça) (Bailey et al., 1986; Faulkner et al., 1990; Waldner et al., 1992; Wilson et al., 1993; Herring et al., 1994; Hamlin et al., 1995; Bergen et al., 1996; Perry \& Fox, 1997). Na literatura alguns estudos indicam que as medidas de ultrasonografia são mais acuradas que as obtidas na carcaça após o abate para a determinação da composição corporal de bovinos (Faulkner et al., 1990; Bullock et al., 1991; Bergen et al., 1996; Hassen et al., 1999; Griffin et al., 1999; May et al., 2000; Suguisawa et al., 2003), enquanto outros demonstram o oposto (Forrest, 1968). Torna-se evidente, portanto, a necessidade de mais estudos nesta área para obtenção de metodologias mais adequadas e práticas.

Neste trabalho, avaliou-se a técnica de ultra-sonografia como potencial ferramenta para predição, com base em medições efetuadas nos animais in vivo, das características determinantes da composição da carcaça de bovinos jovens criados no sistema de produção do novilho superprecoce.

\section{Material e Métodos}

O ensaio experimental foi realizado no setor de confinamento de bovinos de corte da Fazenda Lageado, pertencente à Faculdade de Medicina Veterinária e Zootecnia da UNESP, em Botucatu/SP, no período de 19 de outubro de 2000 a 13 de março de 2001. Foram utilizados 115 bezerros machos não-castrados, com peso médio inicial de $329 \mathrm{~kg}$, de quatro grupos genéticos ( $1 / 2$ Angus Nelore, Canchim, $1 / 2$ Simental Nelore e Nelore) e dois tamanhos à maturidade, totalizando 30 animais de cada cruzamento (15 de tamanho pequeno à maturidade e 15 grandes), à exceção dos animais Nelore, em número de 25 (15 de tamanho pequeno à maturidade e 10 grandes). Os animais foram divididos conforme o tamanho à maturidade (TM), segundo metodologia de Dhuiyvetter (1995), de acordo com a seguinte equação:

$\mathrm{TM}=-11,45+(0,04878 \mathrm{x}$ altura da anca $)-(0,0289 \mathrm{x}$ idade $)+(0,00001947 \mathrm{x} \text { idade })^{2}+(0,0000334 \mathrm{x}$ altura da anca) $\mathrm{x}$ (idade)

Utilizou-se o confinamento da FMVZ, em alvenaria, coberto, com um bebedouro automático por baia e capacidade física para 180 animais, dispostos em 26 baias. Em razão da diferente procedência dos animais, suas respectivas datas de entrada no período de confinamento também foram distintas: mestiços Simental =19/10/2000; mestiços Angus e animais Canchim $=25 / 10 / 2000 ;$ Nelore $=27 / 10 /$ 2000. No início do experimento, todos os animais foram identificados individualmente, tratados contra endo e ectoparasitas (Ivermectina) e distribuídos ao acaso nos currais de confinamento, em grupos de cinco animais, de acordo com a raça e o tamanho, sendo alimentados com dietas isoenergéticas e isoprotéicas, formuladas de acordo com as normas do NRC (1996), nível II (16\% de PB, 74\% de NDT ou 1,14 Mcal/kg de energia líquida), para ganho de peso médio diário de $1,35 \mathrm{~kg}$.

Durante o período de adaptação (15 dias), os animais tiveram livre acesso à água $\mathrm{e}$ foram alimentados duas vezes ao dia (refeições iguais), às 8 e 15h, com dieta contendo relação volumoso:concentrado inicial 40:60, gradativamente aumentada para se evitar possível estresse nutricional nos animais. O consumo de alimentos por baia foi ajustado semanalmente, por meio da pesagem do alimento fornecido e das sobras. Após o período de adaptação, a relação volumoso:concentrado foi de 21:79\% na matéria seca (Tabela 1).

As pesagens e medidas ultra-sonográficas foram realizadas nos animais em jejum (12 horas) antes do abate, segundo metodologia descrita por Herring et al. (1994). Para realização da técnica de ultra-sonografia, efetuou-se a limpeza do local, entre a $12^{\mathrm{a}}$ e $13^{\mathrm{a}}$ costelas do lado esquerdo do animal, e colocou-se óleo vegetal no dorso, para perfeito acoplamento do transdutor, o qual foi disposto de maneira perpendicular ao comprimento do contra-filé (músculo Longissimus dorsi), entre a $12 \underline{a}$ e $13 \underline{a}$ costelas, onde se captura a imagem ultrasonográfica. Durante a leitura da imagem, circundou-se a AOL que aparece no monitor do aparelho, obtendo-se intantaneamente sua medida e da ECG, no terço proximal da imagem do músculo. O equipamento de ultra-sonografia utilizado foi o PIEMEDICAL Scanner 200 VET, com transdutor de 3,5 MHz de $18 \mathrm{~cm}$ e uma guia acústica.

Após 111, 119 e 139 dias de confinamento para os 
Tabela 1 - Composição da dieta fornecida durante o confinamento Table 1 - Diet composition fed to feedlot animals

\begin{tabular}{|c|c|}
\hline $\begin{array}{l}\text { Composição da dieta } \\
\text { Diet composition }\end{array}$ & $\begin{array}{c}\% \text { da matéria seca } \\
\text { Dry matter } \%\end{array}$ \\
\hline Feno de gramínea picado (Chopped grass hay) & 21 \\
\hline ebrado (Craked corn) & 61,5 \\
\hline Farelo de soja (Soybean meal) & 10 \\
\hline Núcleo* (Premix) & 7,5 \\
\hline 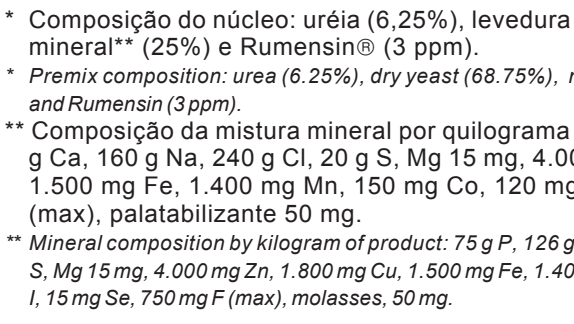 & $\begin{array}{l}\text { ca }(68,75 \%) \text {, mistura } \\
\text { pral composition }{ }^{\star *}(25 \%) \\
\text { pg Zn, } 1.800 \mathrm{mg} \mathrm{Cu}, \\
15 \mathrm{mg} \mathrm{Se}, 750 \mathrm{mg} \mathrm{F} \\
\text { a, } 160 \mathrm{~g} \mathrm{Na}, 240 \mathrm{~g} \mathrm{Cl}, 20 \mathrm{~g} \\
\mathrm{mg} \mathrm{Mn}, 150 \mathrm{mg} \mathrm{Co}, 120 \mathrm{mg}\end{array}$ \\
\hline
\end{tabular}

mestiços Simental, Angus e Canchim para os Nelore, respectivamente, todos os animais foram abatidos no frigorífico FRIGOL de Lençóis Paulista/SP nas seguintes datas: 07/02/2001 = mestiços Simental; 21/02/2001 = mestiços Angus e Canchim; 15/03/2001= animais Nelore. O critério de abate adotado para todos os grupos genéticos foi peso final mínimo de 480 kg e ECG mínima de $3 \mathrm{~mm}$, medida por ultrasonografia. Após o abate, as carcaças foram identificadas, pesadas e resfriadas por 24 horas. Coletaram-se, após o resfriamento, 65 amostras da seção entre a $12^{\underline{a}}$ e $13^{\mathrm{a}}$ costelas de 18 mestiços Angus, 17 animais Canchim, 12 mestiços Simental e 18 animais Nelore, para obtenção das medidas de AOL e ECG na carcaça, realizadas duas semanas após o abate dos animais, no Laboratório de Carnes da UNESP/Botucatu-SP onde as peças permaneceram armazenadas sob resfriamento a $-5^{\circ} \mathrm{C}$. A AOL foi mensurada utilizando-se régua de quadrantes depontos(LuchiariFilho, 2000)eaECG, pormeio demensuração com paquímetro. Após o resfriamento, coletaram-se 71 amostras da secção da 9a à $11^{\mathrm{a}}$ costelas (secção HH) de 18 mestiços Angus, 17 animais Canchim, 18 mestiços Simental e 18 animais Nelore, para estimação da composição corporal, segundo metodologia descrita por Hankins \& Howe (1946), que envolve a separação física dos três principais componentes desta secção (tecidos muscular, adiposo e ósseo), e o cálculo de sua participação percentual na amostra, utilizado para estimativa da composição corporal de toda a carcaça, segundo as equações:

$$
\begin{gathered}
\mathrm{TM}=16,08+0,80 \mathrm{X} \\
\mathrm{TA}=3,54+0,80 \mathrm{X} \\
\mathrm{TO}=5,52+0,57 \mathrm{X}
\end{gathered}
$$

em que TM é a quantidade percentual de tecido muscular; TA, a quantidade percentual de tecido adiposo; TO, a quantidade percentual de tecido ósseo; e X, a porcentagem do respectivo componente na secção $\mathrm{HH}$.
Para verificar a precisão da ultra-sonografia para predição das características de carcaça, foi utilizado o coeficiente de determinação da equação de regressão dos valores observados nos valores preditos, em modelos que incluíram ou não os efeitos de grupo genético. Nestas análises, foram comparados os coeficientes de determinação dos modelos que incluíam as covariáveis preditivas com aqueles que não incluíam estes efeitos, permitindo-se a avaliação do valor preditivo do ultra-som, quando eliminados os efeitos de grupo genético e maturidade. Todas as análises foram realizadas utilizando-se o procedimento GLM do sistema de análises estatísticas SAS (SAS, 1987).

\section{Resultados e Discussão}

Nos estudos da composição de carcaça de bovinos, é fundamental o conhecimento dos fatores determinantes para a expressão das variáveis estudadas. Neste trabalho, foram desenvolvidas equações para análise de quais características poderiam ser mais interessantes para predição dos parâmetros de maior relevância. Supôs-se que as variáveis peso vivo final e peso da carcaça quente, que expressam o tamanho do animal, apresentassem sempre grande importância na predição da quantidade dos principais componentes de carcaça. Não houve efeito significativo $(\mathrm{P}>0,05)$ da idade do animal sobre as características e a composição da carcaça, demonstrando que a correção da idade não proporcionou melhorias na interpretação dos resultados, provavelmente em razão da uniformidade dos grupos genéticos estudados.

$\mathrm{Na}$ Tabela 2 encontram-se os componentes das equações de regressão linear utilizadas para a predição das quantidades dos tecidos adiposo, muscular e ósseo, via ultra-sonografia, apresentados por ordem de importância das variáveis independentes, de acordo com o coeficiente de determinação obtido. Na Tabela 3 constam as equações de predição baseadas nos componentes obtidos na carcaça.

As variáveis peso vivo e ECG por ultra-sonografia (Tabela 2) foram importantes para a predição da quantidade de tecido adiposo e, quando utilizadas em conjunto, aumentaram a precisão da predição desta característica $\left(\mathrm{R}^{2}\right.$ aumentou de 0,27 para 0,44), como demonstrado por diversos autores (Faulkner et al., 1990; Hamlin et al., 1995; Griffin et al., 1999). No entanto, a inclusão da AOL por ultrasonografia provocou aumento irrelevante no coeficiente de determinação da predição desta variável $\left(\mathrm{R}^{2}\right.$ aumentou de $0,64$ para 0,66$)$. Todavia, esta equação de predição da quantidade de tecido adiposo foi tão precisa quanto aquela baseada nas medidas da carcaça $\left(\mathrm{R}^{2}\right.$ de 0,66 , Tabela 3$)$. Apesar disso, quando utilizados somente o peso vivo final 
e a ECG por ultra-sonografia para determinação da quantidade de tecido adiposo da carcaça, os valores dos coeficientes de determinação obtidos neste trabalho foram inferiores aos registrados por Faulkner et al. (1990).

Para determinação da quantidade de tecido muscular, a variável mais importante neste estudo foi o peso vivo final. Ao contrário do esperado, a inclusão da variável AOL por ultra-sonografia não ocasionou grande aumento na acurácia da predição da quantidade de tecido muscular (Tabela 2), como observado por outros autores (Faulkner et al., 1990; Griffin et al., 1999). Segundo Forrest et al. (1968), a AOL para predição da musculosidade sofre grande influência do estádio de crescimento do animal. Para a predição da quantidade de tecido muscular, as medidas obtidas na carcaça foram um pouco mais precisas $\left(\mathrm{R}^{2}=0,86\right.$, Tabela 3) que aquelas determinadas por ultra-sonografia $\left(\mathrm{R}^{2}=0,75\right.$, Tabela 2). Provavelmente, a menor precisão da AOL por ultra-sonografia (Suguisawa et al., 2003) comprometeu estes resultados, como sugerido por Faulkner et al. (1990), que utilizaram somente a variável peso vivo final para determinação da quantidade de músculo na carcaça. Somente o peso vivo final dos animais parece estar diretamente relacionado ao tecido ósseo, como evidenciado por Faulkner et al. (1990).

Na Tabela 4 são apresentados os componentes das equações de regressão para predição das porcentagens dos

Tabela 2 - Componentes das equações de regressão utilizadas para predição da quantidade de tecidos a partir das medidas ultrasonográficas

Table 2 - Regression equation parameters used to predict amount of tissue by ultrasound measurements

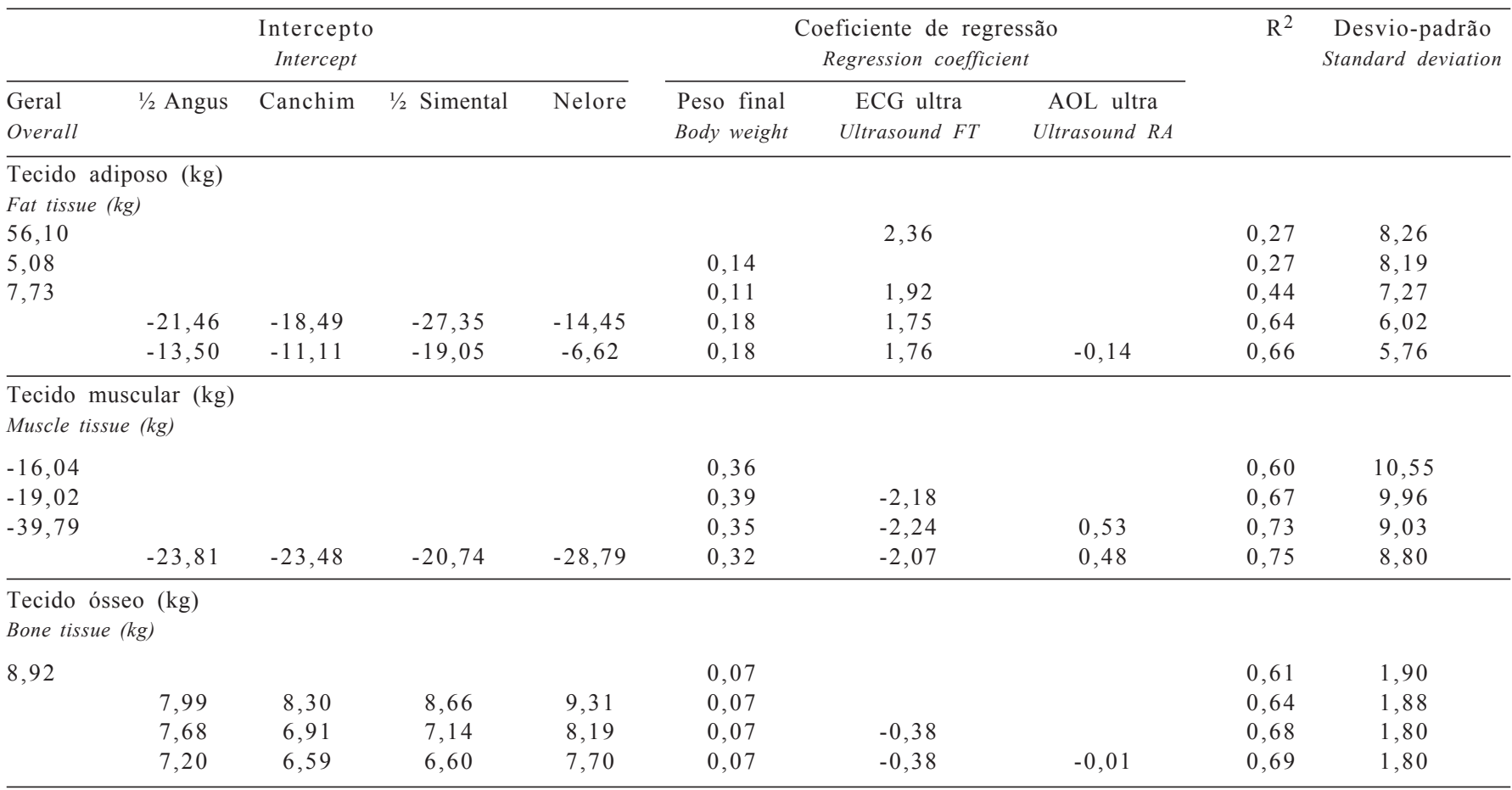

Tabela 3 - Componentes das equações de regressão utilizadas para predição da quantidade de tecidos a partir das medidas da carcaça Table 3 - Regression equation parameters used to predict amount of tissue by carcass measurements

\begin{tabular}{|c|c|c|c|c|c|c|c|c|c|}
\hline \multicolumn{5}{|c|}{$\begin{array}{l}\text { Intercepto } \\
\text { Intercept }\end{array}$} & \multicolumn{3}{|c|}{$\begin{array}{l}\text { Coeficiente de regressão } \\
\text { Regression coefficient }\end{array}$} & \multirow[t]{2}{*}{$\mathrm{R}^{2}$} & \multirow[t]{2}{*}{$\begin{array}{l}\text { Desvio-padrão } \\
\text { Standard deviation }\end{array}$} \\
\hline $\begin{array}{l}\text { Geral } \\
\text { Overall }\end{array}$ & $1 / 2$ Angus & Canchim & $1 / 2$ Simental & Nelore & $\begin{array}{l}\text { Peso carcaça } \\
\text { Carcass weight }\end{array}$ & $\begin{array}{l}\text { ECG carc } \\
\text { Carcass FT }\end{array}$ & $\begin{array}{l}\text { AOL carc } \\
\text { Carcass } R A\end{array}$ & & \\
\hline
\end{tabular}

Tecido adiposo $(\mathrm{kg})$

Fat tissue ( $\mathrm{kg}$ )

\begin{tabular}{|c|c|c|c|c|c|c|c|c|}
\hline$-3,30$ & $-1,98$ & $-0,17$ & 6,86 & 0,34 & 2,13 & $-0,35$ & 0,66 & 5,76 \\
\hline \multicolumn{9}{|l|}{ Tecido muscular $(\mathrm{kg})$} \\
\hline$-14,08$ & $-15,26$ & $-17,94$ & $-23,99$ & 0,55 & $-1,90$ & 0,43 & 0,86 & 5,95 \\
\hline \multicolumn{9}{|l|}{ Tecido ósseo (kg) } \\
\hline 12,38 & 12,29 & 12,91 & 12,21 & 0,13 & $-0,17$ & $-0,06$ & 0,63 & 1,82 \\
\hline
\end{tabular}


tecidos adiposo, muscular e ósseo, calculada a partir das medidas ultra-sonográficas, e, na Tabela 5 , as equações de predição com base nas medidas da carcaça. Grupo genético e ECG por ultra-sonografia parecem ser as variáveis de maior importância para a porcentagem de tecido adiposo na carcaça, conforme sugerido por Bergen et al.(1996). Para predição da porcentagem de tecido adiposo, é importante observar que tanto as equações baseadas nas medidas in vivo obtidas por ultra-sonografia como as baseadas nas medidas realizadas após o abate, apresentaram valores similares para o coeficiente de determinação $\left(\mathrm{R}^{2}=0,52\right.$, Tabela 4 e $\mathrm{R}^{2}=0,53$, Tabela 5), superiores aos reportados por Bailey et al. (1986), que encontraram coeficientes de determinação para as estimativas da porcentagem de gordura de 0,15 ; 0,09 e 0,14 para três categorias de tourinhos analisadas; 340,470 e $600 \mathrm{~kg}$, respectivamente. Entretanto, os trabalhos de Faulkner et al. (1990) e de Perry \& Fox (1997) demonstraram valores de predição superiores ao encontrado neste estudo utilizando somente variáveis como peso vivo final e ECG por ultra-sonografia. Waldner et al. (1992) e Bergen et al. (1996), que desenvolveram equações semelhantes às deste trabalho, com a utilização conjunta de AOL e ECG por ultra-sonografia, obtiveram coeficientes de determinação superiores, de 0,76 e 0,73 , respectivamente.

Para a porcentagem de tecido muscular na carcaça, as variáveis determinantes foram peso vivo final e ECG por ultra-sonografia (Tabela 4). A AOL por ultra-sonografia contribuiu menos que a ECG por ultra-som, confirmando os resultados obtidos por Herring et al. (1994) e Hamlin et al. (1995). Assim, parece que, ao cessar o crescimento corporal dos animais, pára também o crescimento da AOL e a ECG, que, provavelmente, passam a ter maior importância na determinação da quantidade e da porcentagem de tecido muscular. Este fato poderia ser explicado também pela acurácia da estimativa das medidas de AOL por ultrasonografia (Suguisawa et al., 2003), provavelmente em razão do seu aumento em tamanho. Neste trabalho, as medidas obtidas após o abate tiveram maior importância que as mensuradas in vivo por ultra-sonografia para serem utilizadas nas equações de predição da porcentagem e da quantidade de tecido muscular, mesmo apresentando baixos coeficientes de determinação. A porcentagem de tecido ósseo não pode ser determinada por equações baseadas em qualquer variável nem pelas medidas estimadas por ultrasonografia ou na carcaça. Todavia, Faulkner et al. (1990) encontraram coeficiente de determinação alto para a predição desta característica $\left(\mathrm{R}^{2}=0,79\right)$ ao incluírem peso vivo final e ECG por ultra-sonografia no modelo.

Constam na Tabela 6 os componentes das equações de regressão para predição dos rendimentos de carcaça, de cortes cárneos e de traseiro utilizando-se medidas ultrasonográficas e, na Tabela 7 , as equações de predição baseadas nos componentes da carcaça. O rendimento de carcaça foi determinado somente pelas variáveis obtidas na

Tabela 4 - Componentes das equações de regressão para predição da quantidade de tecidos utilizando-se as medidas ultrasonográficas

Table 4 - Regression equation parameters used to predict amount of tissue by ultrasound measurements

\begin{tabular}{|c|c|c|c|c|c|c|c|c|c|}
\hline \multicolumn{5}{|c|}{$\begin{array}{l}\text { Intercepto } \\
\text { Intercept }\end{array}$} & \multicolumn{3}{|c|}{$\begin{array}{c}\text { Coeficiente de regressão } \\
\text { Regression coefficient }\end{array}$} & \multirow[t]{2}{*}{$\mathrm{R}^{2}$} & \multirow[t]{2}{*}{$\begin{array}{l}\text { Desvio-padrão } \\
\text { Standard deviation }\end{array}$} \\
\hline $\begin{array}{l}\text { Geral } \\
\text { Overall }\end{array}$ & $1 / 2$ Angus & Canchim & $1 / 2$ Simental & Nelore & $\begin{array}{l}\text { Peso final } \\
\text { Body weight }\end{array}$ & $\begin{array}{c}\text { ECG ultra } \\
\text { Ultrasound FT }\end{array}$ & $\begin{array}{c}\text { AOL ultra } \\
\text { Ultrasound } R A\end{array}$ & & \\
\hline
\end{tabular}

Tecido adiposo (\%)

Fat tissue (\%)

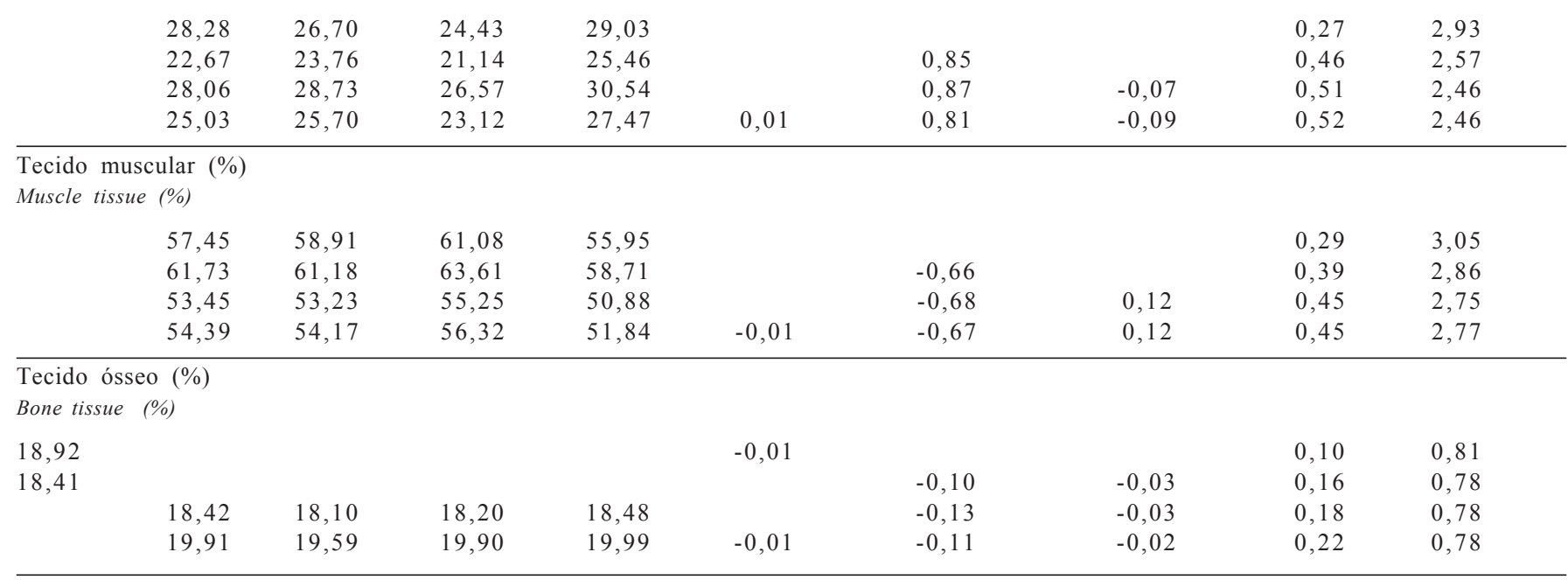


Tabela 5 - Componentes das equações de regressão para predição da quantidade de tecidos utilizando-se as medidas da carcaça Table 5 - Regression equation parameters used to predict amount of tissue by carcass measurements

\begin{tabular}{|c|c|c|c|c|c|c|c|c|c|}
\hline \multicolumn{5}{|c|}{$\begin{array}{l}\text { Intercepto } \\
\text { Intercept }\end{array}$} & \multicolumn{3}{|c|}{$\begin{array}{l}\text { Coeficiente de regressão } \\
\text { Regression coefficient }\end{array}$} & \multirow[t]{2}{*}{$\mathrm{R}^{2}$} & \multirow[t]{2}{*}{$\begin{array}{l}\text { Desvio-padrão } \\
\text { Standard deviation }\end{array}$} \\
\hline $\begin{array}{l}\text { Geral } \\
\text { Overall }\end{array}$ & $1 / 2$ Angus & Canchim & $1 / 2$ Simental & Nelore & $\begin{array}{l}\text { Peso carcaça } \\
\text { Carcass weight }\end{array}$ & $\begin{array}{l}\text { ECG carc } \\
\text { Carcass FT }\end{array}$ & $\begin{array}{l}\text { AOL carc } \\
\text { Carcass } R A\end{array}$ & & \\
\hline
\end{tabular}

Tecido adiposo $(\%)$

Fat tissue (\%)

\begin{tabular}{|c|c|c|c|c|c|c|c|c|}
\hline 26,31 & 26,82 & 27,69 & 30,76 & 0,02 & 0,91 & $-0,13$ & 0,53 & 2,39 \\
\hline \multicolumn{9}{|l|}{$\begin{array}{l}\text { Tecido muscular (\%) } \\
\text { Muscle tissue (\%) }\end{array}$} \\
\hline 52,06 & 51,59 & 50,34 & 47,71 & $-0,01$ & $-0,82$ & 0,16 & 0,55 & 2,45 \\
\hline \multicolumn{9}{|l|}{$\begin{array}{l}\text { Tecido ósseo (\%) } \\
\text { Bone tissue (\%) }\end{array}$} \\
\hline 20,66 & 20,63 & 20,90 & 20,59 & $-0,01$ & $-0,07$ & $-0,03$ & 0,24 & 0,75 \\
\hline
\end{tabular}

Tabela 6 - Componentes das equações de regressão para predição dos rendimentos de carcaça, de cortes cárneos e de traseiro utilizando-se as medidas ultra-sonográficas

Table 6 - Regression equation parameters used to predict yields of carcass, retail cuts and hindquarter by ultrasound measurements

\begin{tabular}{|c|c|c|c|c|c|c|c|c|c|}
\hline \multicolumn{5}{|c|}{$\begin{array}{l}\text { Intercepto } \\
\text { Intercept }\end{array}$} & \multicolumn{3}{|c|}{$\begin{array}{l}\text { Coeficiente de regressão } \\
\text { Regression coefficient }\end{array}$} & \multirow[t]{2}{*}{$\mathrm{R}^{2}$} & \multirow[t]{2}{*}{$\begin{array}{l}\text { Desvio-padrão } \\
\text { Standard deviation }\end{array}$} \\
\hline $\begin{array}{l}\text { Geral } \\
\text { Overall }\end{array}$ & $1 / 2$ Angus & Canchim & $1 / 2$ Simental & Nelore & $\begin{array}{l}\text { Peso final } \\
\text { Body weight }\end{array}$ & $\begin{array}{l}\text { ECG ultra } \\
\text { Ultrasound FT }\end{array}$ & $\begin{array}{l}\text { AOL ultra } \\
\text { Ultrasound } R A\end{array}$ & & \\
\hline
\end{tabular}

Rendimento de carcaça $(\%)$

Carcass yield (\%)

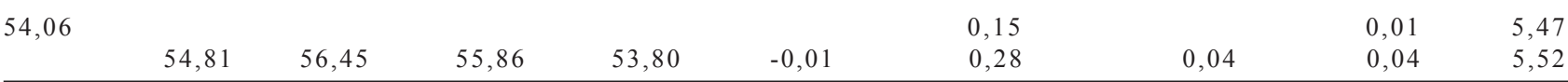

Rendimento de cortes cárneos (\%)

Retail cut yield (\%)

30,22

\begin{tabular}{|c|c|c|c|}
\hline 28,32 & 29,47 & 28,17 & 28,87 \\
\hline 28,53 & 29,24 & 28,40 & 28,50 \\
\hline 28,53 & 29,13 & 28,29 & 29,49 \\
\hline
\end{tabular}

$\begin{array}{llll}-0,01 & & 0,20 & 0,97 \\ -0,01 & & 0,27 & 0,95 \\ -0,01 & 0,01 & 0,27 & 0,97 \\ -0,01 & 0,01 & 0,28 & 0,97\end{array}$

Rendimento de traseiro (\%)

Hindquarter yield (\%)

\begin{tabular}{|c|c|c|c|c|c|c|c|c|}
\hline 61,55 & 61,13 & 59,45 & 59,87 & & & & 0,29 & 1,41 \\
\hline 69,18 & 68,44 & 67,55 & 67,23 & $-0,02$ & & & 0,39 & 1,32 \\
\hline 69,28 & 69,19 & 68,37 & 67,85 & $-0,02$ & 0,20 & & 0,42 & 1,29 \\
\hline 70,27 & 70,05 & 69,37 & 68,78 & $-0,02$ & 0,20 & $-0,02$ & 0,43 & 1,28 \\
\hline
\end{tabular}

carcaça após o abate, entretanto, os valores de coeficiente de determinação foram insignificantes. O rendimento de cortes cárneos, por sua vez, foi determinado principalmente pelas variáveis peso vivo e raça do animal, como mencionado anteriormente. Apesar de as equações baseadas nas variáveis in vivo por ultra-sonografia terem apresentado coeficiente de determinação similar ao daquelas baseadas nas variáveis da carcaça, os valores obtidos por ambas as equações foram baixos. Embora May et al. (2000) tenham concluído que os resultados obtidos pela técnica de ultrasonografia são bastante aceitáveis e muitas vezes superiores aos das equações baseadas somente nas características obtidas na carcaça após o abate dos animais, este comportamento não foi evidenciado neste trabalho, provavelmente em razão da menor precisão da predição da AOL por ultrasonografia (Suguisawa et al., 2003), visto que na literatura foram encontrados muitos trabalhos indicando que a predição do rendimento de cortes cárneos sofre significativa influência da medida de AOL por ultra-sonografia (Waldner et al., 1992; Perry \& Fox, 1997).

Os coeficientes de determinação para as equações de predição do rendimento de cortes cárneos deste estudo foram inferiores aos encontrados por Herring et al. (1994), de 0,29 a 0,48; Hamlin et al. (1995), de 0,61 a 0,65; Griffin et al. 
Tabela 7 - Componentes das equações de regressão para predição dos rendimentos de carcaça, de cortes cárneos e de traseiro utilizando-se as medidas otidas na carcaça

Table 7 - Regression equation parameters used to predict yields of carcass, retail cuts, and hindquarter by carcass measurements

\begin{tabular}{|c|c|c|c|c|c|c|c|c|c|}
\hline \multicolumn{5}{|c|}{$\begin{array}{l}\text { Intercepto } \\
\text { Intercept }\end{array}$} & \multicolumn{3}{|c|}{$\begin{array}{c}\text { Coeficiente de regressão } \\
\text { Regression coefficient }\end{array}$} & \multirow[t]{2}{*}{$\mathrm{R}^{2}$} & \multirow[t]{2}{*}{$\begin{array}{l}\text { Desvio-padrão } \\
\text { Standard deviation }\end{array}$} \\
\hline $\begin{array}{l}\text { Geral } \\
\text { Overall }\end{array}$ & $1 / 2$ Angus & Canchim & $1 / 2$ Simental & Nelore & $\begin{array}{l}\text { Peso carcaça } \\
\text { Carcass weight }\end{array}$ & $\begin{array}{l}\text { ECG carc } \\
\text { Carcass FT }\end{array}$ & $\begin{array}{l}\text { AOL carc } \\
\text { Carcass } R A\end{array}$ & & \\
\hline
\end{tabular}

Rendimento de carcaça (\%)

Carcass yield (\%)

$\begin{array}{lllllllll}46,12 & 46,51 & 44,26 & 46,30 & 0,02 & -0,18 & 0,06 & 0,32 & 1,38\end{array}$

Rendimento de cortes cárneos $(\%)$

Retail cut yield (\%)

\begin{tabular}{|c|c|c|c|c|c|c|c|c|}
\hline 27,70 & 28,26 & 27,39 & 27,89 & $-0,02$ & $-0,02$ & 0,03 & 0,25 & 0,98 \\
\hline \multicolumn{9}{|c|}{$\begin{array}{l}\text { Rendimento de traseiro (\%) } \\
\text { Hindquarter yield (\%) }\end{array}$} \\
\hline 68,19 & 67,81 & 67,68 & 68,07 & $-0,05$ & 0,31 & 0,04 & 0,48 & 1,22 \\
\hline
\end{tabular}

(1999), de 0,17 a 0,52; Hassen et al. (1999), de 0,59 a 0,76 para terminação constante; e de May et al. (2000), de 0,66.

Constatou-se que a raça é a variável de maior importância para predição da porcentagem de traseiro. Neste caso, as equações baseadas nas medidas in vivo por ultra-sonografia apresentam coeficiente de determinação ligeiramente inferior ao daquelas baseadas nas mesmas medidas realizadas na carcaça após o abate, entretanto, com baixos coeficientes de determinação.

Na Tabela 8 encontram-se os componentes das equações de regressão utilizadas para predição da quantidade de cortes cárneos e de traseiro baseadas nas medidas ultrasonográficas e, na Tabela 9, as equações de predição baseadas nos componentes da carcaça. O peso vivo final foi a variável mais importante para predição da quantidade de cortes cárneos. Como esperado, o mesmo comportamento foi observado na predição da quantidade de traseiro. De qual- quer modo, para ambas as características, as equações baseadas nas medidas in vivo por ultra-sonografia apresentaram coeficiente de determinação similar ao daquelas estimadas utilizando-se as medidas realizadas na carcaça após o abate.

Embora os coeficientes de determinação das equações de predição baseadas nas medidas in vivo por ultrasonografia tenham apresentado grande variação e não tenham sido elevados $\left(\mathrm{R}^{2}=0,04\right.$ e $\mathrm{R}^{2}=0,89$, Tabelas 6 e 8 , respectivamente), as equações de predição baseadas somente nas medidas obtidas na carcaça após o abate também apresentaram grande variação e valores não muito superiores $\left(\mathrm{R}^{2}=0,24\right.$ a $\mathrm{R}^{2}=0,92$, Tabelas 5 e 9 , respectivamente). Sabendo-se que a ultra-sonografia não apresentou alta precisão na predição da AOL da carcaça (Suguisawa et al., 2003), justificando, em parte, a baixa acurácia na predição da quantidade e porcentagem de tecido muscular e, conseqüentemente, na predição do rendimento de cortes cárneos, de maneira geral, os coefi-

Tabela 8 - Componentes das equações de regressão para predição da quantidade de cortes cárneos e de traseiro utilizando-se as medidas ultra-sonográficas

Table 8 - $\quad$ Regression equation parameters used to predict amount of retail cuts and hindquarter by ultrasound measurements

\begin{tabular}{|c|c|c|c|c|c|c|c|c|c|}
\hline \multicolumn{5}{|c|}{$\begin{array}{l}\text { Intercepto } \\
\text { Intercept }\end{array}$} & \multicolumn{3}{|c|}{$\begin{array}{c}\text { Coeficiente de regressão } \\
\text { Regression coefficient }\end{array}$} & \multirow[t]{2}{*}{$\mathrm{R}^{2}$} & \multirow[t]{2}{*}{$\begin{array}{l}\text { Desvio-padrão } \\
\text { Standard deviation }\end{array}$} \\
\hline $\begin{array}{l}\text { Geral } \\
\text { Overall }\end{array}$ & $1 / 2$ Angus & Canchim & $1 / 2$ Simental & Nelore & $\begin{array}{l}\text { Peso final } \\
\text { Body weight }\end{array}$ & $\begin{array}{c}\text { ECG ultra } \\
\text { Ultrasound FT }\end{array}$ & $\begin{array}{c}\text { AOL ultra } \\
\text { Ultrasound } R A\end{array}$ & & \\
\hline
\end{tabular}

Cortes cárneos $(\mathrm{kg})$

Retail cut weight $(\mathrm{kg})$

\begin{tabular}{|c|c|c|c|c|c|c|c|c|}
\hline 8,21 & & & & 0,05 & & & 0,60 & 1,44 \\
\hline 4,79 & 5,94 & 4,37 & 5,14 & 0,06 & & & 0,65 & 1,38 \\
\hline 2,96 & 4,22 & 2,67 & 3,50 & 0,05 & & 0,04 & 0,67 & 1,37 \\
\hline 2,91 & 3,75 & 2,14 & 3,12 & 0,05 & $-0,14$ & 0,04 & 0,68 & 1,36 \\
\hline
\end{tabular}

Traseiro $(\mathrm{kg})$

Hindquarter weight $(\mathrm{kg})$

11,99

$\begin{array}{lllll}6,12 & 6,18 & 5,42 & 6,46 & 0,14 \\ 5,61 & 5,67 & 3,38 & 4,43 & 0,14 \\ 5,61 & 5,64 & 3,34 & 4,40 & 0,14\end{array}$

$\begin{array}{llll}0,14 & & 0,83 & 2,29 \\ 0,15 & & 0,87 & 2,04 \\ 0,14 & 0,08 & 0,89 & 1,90 \\ 0,14 & 0,01 & 0,89 & 1,92\end{array}$


Tabela 9 - Componentes das equações de regressão para predição da quantidade de cortes cárneos e de traseiro utilizando-se as medidas obtidas na carcaça

Table 9 - Regression equation parameters used to predict amount of retail cuts and hindquarter by carcass measurements

\begin{tabular}{|c|c|c|c|c|c|c|c|c|c|}
\hline \multicolumn{5}{|c|}{$\begin{array}{l}\text { Intercepto } \\
\text { Intercept }\end{array}$} & \multicolumn{3}{|c|}{$\begin{array}{c}\text { Coeficiente de regressão } \\
\text { Regression coefficient }\end{array}$} & \multirow[t]{2}{*}{$\mathrm{R}^{2}$} & \multirow[t]{2}{*}{$\begin{array}{l}\text { Desvio-padrão } \\
\text { Standard deviation }\end{array}$} \\
\hline $\begin{array}{l}\text { Geral } \\
\text { Overall }\end{array}$ & $1 / 2$ Angus & Canchim & $1 / 2$ Simental & Nelore & $\begin{array}{l}\text { Peso carcaça } \\
\text { Carcass weight }\end{array}$ & $\begin{array}{l}\text { ECG carc } \\
\text { Carcass } F T\end{array}$ & $\begin{array}{l}\text { AOL carc } \\
\text { Carcass } R A\end{array}$ & & \\
\hline
\end{tabular}

Cortes cárneos $(\mathrm{kg})$

Retail cut weight $(\mathrm{kg})$

4,48

5,13

4,03

4,73

0,09

$-0,02$

0,03

0,71

1,23

Traseiro $(\mathrm{kg})$

Hindquarter weight $(\mathrm{kg})$

9,84

9,28

8,94

9,65

0,24

0,35

0,06

0,92

1,58

cientes de determinação das equações de predição das características da composição da carcaça pelas medidas ultrasonográficas foram similares e, para a predição da quantidade de ossos da carcaça $\left(\mathrm{R}^{2}=0,69\right.$, Tabela 2$)$, foi superior àqueles obtidos com as equações baseadas nas medidas na carcaça após o abate, indicando que a ultra-sonografia pode ser utilizada para predição da composição da carcaça de bovinos em determinadas situações, como demonstrado por Faulkner etal.(1990), Bullock etal.(1991)e Bergen etal.(1996). Este fato indica que o erro na predição da AOL não decorreu necessariamente de falhas na técnica de ultra-sonografia, podendo ter sido causado também por diferenças naturais entre as medidas tomadas na carcaça e no animal vivo.

\section{Conclusões}

Apesar de a ultra-sonografia não ter apresentado alta precisão na predição da musculosidade da carcaça e do rendimento dos cortes cárneos, de maneira geral, os coeficientes de determinação das equações de predição da composição da carcaça baseados na ultra-sonografia foram semelhantes àqueles obtidos nas equações que utilizaram as mesmas medidas na carcaça após o abate, demostrando que o ultra-som pode ser utilizado para predição de alguns parâmetros da composição da carcaça.

\section{Literatura Citada}

ALLEONI, G.F.; LEME, P.R.; BOIN, C. et al. Avaliação da composição química e física dos cortes da costela para estimar a composição química corporal de novilhos Nelore. Revista Brasileira de Zootecnia, v.26, p.382-390, 1997.

BAILEY, C.; JENSEN, J.; BECH ANDERSEN, B. Ultrasonics scanning and body measurements for predicting composition and muscle distribution in young Holstein $x$ Friesian bulls. Journal of Animal Science, v.63, p.1337-1346, 1986.

BERGEN, R.D.; McKINNON, J.J.; CHRISTENSEN, D.A. et al. Prediction of lean yield in yearling bulls using real-time ultra-sound. Canadian Journal of Animal Science, v.76, p.305-311, 1996.
BULLOCK, K.D; BERTRAND, J.K.; BENYSHEK, L.L. et al. Comparison of real-time ultrasound and other live measures to carcass measures as predictors of beef cow energy stores. Journal of Animal Science, v.69, p.3908-3916, 1991.

DHUYVETTER, J. Beef cattle frame scores. Fargo: NDSU, 1995. $2 p$

FAULKNER, D.B.; PARRET, D.F.; McKEITH, F.K. et al. Prediction of fat cover and carcass composition from live and carcass measurements. Journal of Animal Science, v. 68 , p.604-610, 1990.

FISHER, A. A review of the technique of estimating the composition of livestock using the velocity of ultrasound. Computers and Electronics in Agriculture, v.17, p.217-231, 1997.

FONTES, C.A.A. Composição corporal, exigências líquidas de nutrientes para ganho de peso e desempenho produtivo de animais zebuínos e mestiços Europeu-Zebu. Resultados experimentais. In: SIMPÓSIO INTERNACIONAL SOBRE EXIGÊNCIAS NUTRICIONAIS DE RUMINANTES, 1., 1995, Viçosa, MG. Anais... Viçosa, MG: Sociedade Brasileira de Zootecnia, 1995. p.419-465.

FORREST, R.J. Comparison of several methods of estimating the fat and the lean composition of bovine rib cuts. Canadian Journal of Animal Science, v.48, p.103-108, 1968.

GRIFFIN, D.B.; SAVELL, J.W.; RECIO, H.A. et al. Predicting carcass composition of beef cattle using ultrasound technology. Journal of Animal Science, v.77, p.889-892, 1999.

HAMLIN, K.E.; GREEN, R.D.; CUNDIFF, L.V. et al. Real-time ultrasonic measurement of fat thickness and longissimus muscle diameter: II. Relationships between real-time ultrasound measures and carcass retail yield. Journal of Animal Science, v.73, p.1725-1734, 1995.

HANKINS, O.G.; HOWE, P.E. Estimation of the composition of beef cattle carcasses and cuts. Washington: USDA, 1946. (Technical Bulletin, 926)

HASSEN, A.; WILSON, D.E.; ROUSE, G.H. Evaluation of carcass, live, and real-time ultrasound measures in feedlot cattle: II. Effects of different age end points on the accuracy of predicting the percentage of retail product, retail product weight, and hot carcass weight. Journal of Animal Science, v.77, p.283-290, 1999.

HERRING, W.O.; MILLER, D.C.; BERTRAND, J.K. et al. Evaluation of machine, technician, and interpreter effects on ultrasonic measures of backfat and longissimus muscle area in beef cattle. Journal of Animal Science, v.72, p.2216-2226, 1994.

HOPPER, T.H. Methods of estimating the physical and chemical composition of cattle. Journal of Agricultural Research, v.68, p.6-23, 1944.

JORGE, A.M.; FONTES, C.A.A.; SOARES, J.E. et al. Características quantitativas da carcaça de bovinos e bubalinos, abatidos em diferentes estádios de maturidade. Revista Brasileira de Zootecnia, v.26, p.1039-1047, 1997. 
JORGE, A.M.; FONTES, C.A.A. Composição física da carcaça de bovinos e bubalinos abatidos em diferentes pesos. In: CONGRESSO BRASILEIRO DE CIÊNCIA E TECNOLOGIA DE CARNES, 1., São Pedro, 2001. Anais... Campinas: Instituto de Tecnologia de Alimentos, 2001. p.82-83.

LANNA, D.P.D. Estimativa da composição química do corpo vazio de tourinhos Nelore através da gravidade específica da carcaça e da composição de cortes das costelas. Piracicaba, 1988. 131p. Dissertação (Mestrado em Ciência Animal e Pastagens) - Escola Superior de Agricultura Luiz de Queiroz, Universidade de São Paulo.

LANNA, D.P.D.; BOIN, C.; ALLEONI, G.F. et al. Estimation of carcass and empty body composition of Zebu bulls using the composition of rib cuts. Scientia Agricola, v.52, p.189-97, 1995.

LUCHIARI FILHO, A. Pecuária da carne bovina. São Paulo: LinBife, 2000. 134p.

LUSH, J.L. Pratical methods of estimating the proportions of fat and bone in cattle slaughtered in commercial packing plants. Journal of Agricultural Research, v.32, p.727-755, 1926.

MAY, S.G.; MIES, W.L.; EDWARDS, J.W. et al. Using live estimates and ultrasound measurements to predict carcass cutability. Journal of Animal Science, v.78, p.1255-1261, 2000.

NATIONAL RESEARCH COUNCIL - NRC. Nutrient requirements of beef cattle. 7.ed. Washington, D.C.: National Academy Press, 1996. 242p.
PERRY, T.C.; FOX, D.G. Predicting carcass composition and individual feed requirement in live cattle widely varying in body size. Journal of Animal Science, v.75, p.300-307, 1997.

STATISTICAL ANALYSES SYSTEM - SAS. SAS/STATTM guide for personal computers. 6.ed. Cary: 1987. 1028p.

SUGUISAWA, L.; MATTOS, W.R.S.; OLIVEIRA, H.N.O. et al. Ultrasonography as a predicting tool for carcass traits of Young bulls. Scientia Agricola, v.60, n.4, p.779-784, 2003.

WALDNER, D.N.; DIKEMAN, M.E.; SCHALLES, R.R. et al Validation of real-time ultrasound technology for predicting fat thickness, longissimus muscle areas, and composition of Brangus bulls from 4 months to 2 years of age. Journal of Animal Science, v.70, p. 3044-3054, 1992.

WILSON, D.E.; WILLHAM, R.L.; NORTHCUTT, S.L. et al. Genetic parameters for carcass traits estimated from Angus field records. Journal of Animal Science, v.71, p.2365-2370, 1993.

Recebido: $16 / 09 / 04$ Aprovado:30/08/05 